\title{
Vozes em curso
}

ENSAIO

Voices in progress

Caleb Faria Alves ${ }^{a}$

\section{Editores}

Maria Inês Côrte Vitoria PUCRS, Brasil

Pricila Kohls dos Santos PUCRS, Brasil

\section{Equipe Editorial}

Carla Spagnolo

PUCRS, RS, Brasil

Marcelo Oliveira da Silva

PUCRS, RS, Brasil

Rosa Maria Rigo

PUCRS, RS, Brasil

ISSN 2179-8435

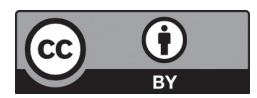

A matéria publicada neste periódico é licenciada sob forma de uma Licença Creative Commons - Atribuição 4.0 Internacional.

http://creativecommons.org/licenses/by/4.0/
- 1 ste texto nasce de um convite: falar sobre minha experiência como professor. O que me Chabilita, nesse caso, é simplesmente ter exercido a profissão: sou testemunha histórica, como cada um em sua área, do que vivenciei. Todo testemunho, para ser útil, deve ser algo ingênuo: mostrar a interpretação limitada, mas pessoalmente pertinente que me permitiu atribuir sentido e orientação ao que passei. Isso não que dizer, entretanto, que minha manifestação, como qualquer outra, tenha um conteúdo puramente pessoal ou particular. Temos tendência a explicar nossas ações como posicionamentos possíveis em relação a um sistema social, e entendemos suas consequências como resultado de forças em movimento circunscritas a uma temporalidade. Essa sociologia espontânea é elaborada em confronto com as interprestações que nos são fornecidas pelas pessoas com as quais partilhamos essas experiências. Nas páginas seguintes, procurei, justamente, relembrar esses confrontos.

Quem revê suas memórias, nesse sentido, sempre constrói um tipo social, um personagem de si mesmo que se projeta como central a um momento histórico porque é partir dele que enxergamos e compreendemos o passado. Sua importância na narrativa do tempo decorre da nossa necessidade de nos sentirmos protagonistas de nossas próprias vidas. A história, no entanto, nos ensina o inverso: há outras possibilidades de existência paralelas à nossa, não as consideramos simplesmente porque não as conhecemos ou não entendemos suas dimensões. Meus pontos cegos constituem, entretanto, dado importante. $\mathrm{O}$ que me falta, me falta por alguma razão: evidencia, portanto, características da dinâmica social. Tanto pelos meus equívocos, quanto pela minha lucidez, me aproximo, como exemplo pulsante, dos condicionantes do convívio no ambiente escolar que passo a rememorar.

a Possui graduação em Ciências Sociais pela Universidade de São Paulo (1990) e doutorado em Sociologia pela Universidade de São Paulo (2001). Atualmente é professor adjunto 1 da Universidade Federal do Rio Grande do Sul. 
A pergunta que faço a mim mesmo, para começar a conversa, é: através de que recursos eu me fiz professor? Não me refiro, claro, ao investimento institucional num cargo ou função, mas sim às opções de postura que permitiam a mim mesmo conceber-me no papel de professor. A fonte primeira da composição dessa autoimagem foram os modelos tirados da minha própria formação. O modo como os professores reagem as às demandas discentes, demandam tarefas, explicam, orientam carreiras, são alguns dos principais elementos a partir dos quais os alunos compõem esboços de como serão suas vidas futuras, seja por sua rejeição ou aproveitamento. O processo é ainda mais acentuado se almejam o magistério. Os professores alimentam essas imagens oferecendo, no palco da sala de aula, a si mesmos como intérpretes de seu próprio passado como alunos. Eles nunca estão, portanto, simplesmente realizando uma tarefa. Ninguém exerce essa profissão sem colocar um pouco de si mesmo em tudo que faz, sem recorrer ao que o formou como profissional, sem refletir como essa constituição trará consequências no exercício futuro das atividades dos seus alunos. É dentro dessa perspectiva que vou desenvolver esse texto. Vou discorrer sobre como entendo essa troca: tentarei tornar explícitas as orientações que adotei no exercício dos cargos que ocupei e a percepção que tenho de como fui afetado e de como afetei outras pessoas neste processo.

Comecei a dar aulas muito cedo, aos 19 anos de idade, recém ingresso na vida universitária. Trabalhava num curso supletivo noturno no centro de São Paulo, na Rua Rêgo Freitas, dentro da região conhecida como Boca do Lixo. Os alunos, em sua maioria, eram office-boys, empregados nos bares ou auxiliares de escritório. Algumas das alunas eram prostitutas e aproveitavam o período anterior ao turno nas boates para estudar.

Claro que não estava preparado, menos ainda para esse perfil de alunos, mas devido à carência de professores, a legislação abria a possibilidade de contratação de graduandos. Eu ministrava Organização Social e Política Brasileira, disciplina extinta em 1993, se não me engano, e que, juntamente com Educação Moral e Cívica, formava o par imposto pela ditadura militar para difusão de seus ideais. Assumir as aulas, nesse sentido, representou um drama ético para mim. Não queria cumprir com uma orientação que eu deplorava, mas não sabia onde encontrar material alternativo adequado àquela turma e ao que eu gostaria de discutir com eles. Justificar minha presença ali dependia de uma solução para esse problema. Era impossível ver a mim mesmo como reprodutor de estruturas que eu repudiava.

Como todos sabem, não havia espaços na mídia, no mercado editorial ou em eventos públicos para debates francos e abertos sobre o quadro político e social brasileiro, menos ainda uma produção didática afinada com essa perspectiva. O mundo da oficialidade, do reconhecido, do institucionalizado, gerava desconfiança. Participar de algo burocraticamente sancionado levantava suspeitas de aliança com o estado opressor. A subversão, nesse sentido, não era apenas uma atitude de guerrilheiros, de extremistas, de comunistas. Era um valor, uma postura ética para além, inclusive, da política propriamente dita. Gostávamos de cantores, bares, exposições, comportamentos, leituras que 
entendíamos como aviltantes a um inimigo comum e mal definido, o sistema. Saber de uma festa ou encontro via folheto ou convite aberto, já era um desânimo, indicava que não valia tanto a pena comparecer. O que nos excitava era o boca a boca, o sussurro. Ficávamos contentes de sermos reconhecidos como elos nas cadeias informais de comunicação.

Lembro, por exemplo, quando assistimos, na sala do centro acadêmico, a uma cópia do filme Je vous salue Marie, do Godard, lançado em 1985 e censurado no Brasil. Tenho ainda uma vívida recordação do meu olhar errando na penumbra pela cordilheira de joelhos e cabeças dos meus colegas sentados no chão, todos cuidando quem estava dentro da sala e, sobretudo, vigiando a porta. Não recebemos um resumo do filme antes de iniciar a sessão, não fizemos debates abertos sobre o que vimos e nem escutamos referências diretas a ele em publicações. Houve algum espaço para contestação pública à censura, mas o que o filme mostrava de contestador não era tão evidente: não era um discurso direto contra opressão e controle ditatorial. Na verdade, nem mesmo sabíamos se havia realmente algum perigo em assistir àquele filme. O que nos movia, então? Para usar um jargão mal aplicado, a rebeldia estava no ar.

Nesse sentido, a subversão ia muito além do que hoje é mostrado nos filmes sobre a ditadura ou nos depoimentos de guerrilheiros. Não se reduzia ao inconformismo político, ao desafio aos pais no comportamento sexual ou no consumo de drogas. Estava presente nas coisas mais simples do cotidiano, até nas nossas diversões. Nossa sociabilidade, nossas emoções, nossas expectativas giravam em torno desse tipo de evento. Mencionei um filme, mas poderia ser um livro, um texto, uma conversa com um artista, um líder político. Nos entreolhávamos indagando: é subversivo? De que forma? Como saber? O que pensam meus amigos? Não quero insinuar que éramos todos simpáticos à esquerda. A maioria era estudantes de ciências sociais não poderiam ser favoráveis àquele regime que perseguia seus próprios professores. De qualquer jeito, essas perguntas emergiam qualquer que fosse a filiação política do envolvido ou a intenção do ato. Não quero, portanto, iludir nem a mim nem aos leitores quanto a um passado pleno de compromisso social e de engajamento. Não é disso que se trata. Quero apenas salientar que nossos hábitos de convivência e comportamento giravam em torno da possibilidade do subversivo.

Apesar das dificuldades e de não saber exatamente o que fazer ou a quem recorrer para pedir ajuda, eu estava muito empolgado com minha turma. Uma das principais características desse ambiente de meias palavras era o enorme prestígio do investimento intelectual em grupos pequenos, quase invisíveis. O chamado "trabalho de formiguinha" era uma missão honrosa. Assim, ministrar aulas para aqueles alunos na Rua Rêgo Freitas, era, para mim, uma grande oportunidade. Muitos dos meus heróis intelectuais desenvolveram seus trabalhos junto a públicos semelhantes: ministravam aulas em sindicatos, grupos de estudos na periferia, comunidades eclesiais de base, etc. Eu me via em diálogo direto com eles, com uma experiência própria. 
Esse ânimo todo não se restringia à universidade, ao meio acadêmico ou sequer era característico da militância. A trilha sonora do meu ensino médio e da graduação foi Another brick in the wall, do Pink Floyd. Queríamos nos contrapor, seja como alunos, seja como professores, a um ensino que produzia tijolos de um sistema social injusto, em vez do conhecimento e crítica que fariam ruir seus muros (Descobri, mais tarde, um pouco chocado, que essa música chegou a ser a segunda mais tocada nas rádios brasileiras nos anos 1980. Percebi, com isso, que minha identidade passava, em alguma medida, pela mídia.). Nem todos, por causa disso, aderiram à militância política, alguns usavam a crítica como álibi para um descompromisso com qualquer causa que fosse. Outros tratavam a esquerda política também como uma forma de autoritarismo que não representava avanço democrático nenhum. Havia toda uma gama de posicionamentos que se pensavam como contestatórios. Seria difícil listar todos. As visões desse período tendem a ressaltar esse ou aquele como mais significativo e a apagar os outros.

O que desejo destacar é que havia um clima geral de consideração, prestígio e estabelecimento de laços, muito diferente do experimentado hoje em dia, embora, como veremos adiante, com dilemas e questões parecidas. Um ambiente é conformado por saberes, comportamentos, expectativas tácitas. Elas definem o que é tratado publicamente ou no âmbito particular, nos informam o teor das conversas de corredor, dos papos regados a cerveja, das disputas no Centro Acadêmico. Definem, também, a dinâmica das aulas e, consequentemente, dos modelos de comportamento que utilizaríamos depois como professores. No caso que estamos discutindo, esses fatores eram perpassados pelo fantasma da opressão.

Voltando à escola na Rêgo Freitas: como, nesse clima, eu podia definir uma orientação para as aulas que assumi? Uma primeira conversa que tive com o diretor da escola sobre o conteúdo da disciplina permitiu que eu vislumbrasse alguma perspectiva de atuação. Eu teria liberdade para definir o material que achasse mais adequado. Ou seja, apesar da evidente orientação de direita na própria existência daquela matéria, eu não seria submetido a nenhum controle rígido quanto aos temas e abordagem, não seria obrigado a adotar nenhum livro didático específico. Essas brechas me permitiram conceber a disciplina como oportunidade para difusão de conteúdos contrários àqueles que orientaram sua criação, ou seja, um espaço para o desenvolvimento de posturas críticas ao sistema político vigente. Faltava agora uma referência de programa para a disciplina.

Como estudante de ciências sociais, não era tão difícil formular em termos mais genéricos e abstratos o que eu pretendia: construir um ambiente participativo de aprendizado que incorporasse as experiências dos alunos em respeito às suas condições sócio culturais e capaz de despertar neles uma postura crítica. Precisava desmembrar isso em atividades pedagógicas. O que eu visava, entretanto, não era nenhuma mensagem explícita. No meio acadêmico, ou fora dele, respeitávamos discursos nos quais entendíamos mensagens cifradas a favor da democracia. Estávamos acostumados a examinar o que havia por trás do discurso direto. 
Meu hábito me conduzia a tentar preparar exposições com conteúdos velados, esses sim, importantes. O treino mais forte nessa prática vinha das canções de amor da MPB. Quem te viu, quem te vê, de Chico Buarque, era cantada nas passeadas contra o governo em alusão a um futuro democrático. Mas havia inúmeras outras. Era uma forma de se comunicar, de criticar sem ser censurado: fazer de conta que se falava de amor. No caso, eu precisa encontrar um conteúdo de "faz de conta" pertinente à disciplina no qual eu pudesse plantar insinuações sobre outras questões que realmente me interessavam. Desafio imenso e, assim colocado, bastante ingênuo.

Através das rodas informais de conversas, do contato com outros colegas que procuravam o mesmo que eu e enfrentavam os mesmos desafios, eu consegui um livro fortemente recomendado cujo título era bastante ousado: Cuidado, Escola!. Publicado pela primeira vez em 1980, pela Brasiliense, foi escrito pela equipe do Instituto de Ação Cultural, fundado pelo Paulo Freire na Suíça. Minha primeira impressão foi a de que tinha encontrado as notas de rodapé para a letra do Roger Waters, os caminhos intelectuais para desmontar o muro cantado pelo Pink Floyd. Foi também a primeira vez que li algo do Paulo Freire. Já tinha ouvido falar dele por alguns colegas que ministravam aulas numa favela nas imediações da USP utilizando o seu método. De sua autoria, apenas uma página de apresentação, escrita pouco antes dele retornar do exílio, mas introduzia o livro e abria um nova dimensão profissional para mim.

Foi com essa leitura que primeiro aprendi que a escola não realiza bem ou mal suas atividades, ela é um subsistema de outro maior. O livro era cheio de ilustrações, humor, dados históricos, depoimentos de pais e alunos, ou seja, uma produção moderna, instigante, pensada para ser usada por pais, alunos, estudantes, pedagogos, como livro didático, como literatura. O texto teve uma difusão enorme. Parecia responder a boa parte das nossas dúvidas e anseios de conteúdos programáticos. Finalmente eu tinha uma referência passível de ser trabalhada com aqueles alunos. Encontrara o material que atendia às minhas expectativas: fornecia um guia de atuação como professor ao mesmo tempo que elementos a serem ensinados.

Eu me identificava pessoalmente, e com profundo alívio, com os depoimentos transcritos logo nas primeiras páginas do livro. A frase: "paciência, vai ser empregado como eu", poderia ter sido dita por meu pai ou minha mãe. A análise poderia se resumir na imagem da escola como imenso funil cuja função não é incluir ou ensinar, mas eliminar a maioria de qualquer chance competitiva pelos cargos mais bem pagos no mercado de trabalho. Expulsar do sistema educacional os oriundos de classes mais baixas através de conteúdos estranhos ao seu universo, da valorização de conhecimentos extracurriculares, como o de línguas estrangeiras, do elogio de um saber canônico, distante e vazio, de uma postura rígida e disciplinadora por parte dos professores.

Hoje é fácil perceber o simplismo presente na estrutura geral do daquela produção. O livro começa com críticas ao ensino através de dados estatísticos, destacando o pequeno número que chega à universidade (em 1980, apenas 
14 em cada 100 estudantes), mas usava também elementos discursivos que eu nunca imaginara que fariam par com a seriedade dos números, as charges (na página 11, por exemplo, estudantes correm assustados de nuvens negras que soltam raios). Em seguida, nos apresentava a história da escola. De modo romântico, começava com o antes da escola propriamente dita, um ambiente de aldeia, quando todos sabiam e ensinavam no curso do próprio viver. Nas etapas seguintes essa realidade era esmagada por uma sequência que desembocava teleologicamente na divisão de classes após sucessivas fases de sistemas de dominação. O título do último capítulo: A raiz do problema não estaria fora da escola?, sugeria que a solução para certos problemas educacionais dependiam da reestruturação do modo de produção e de organização social.

Eu começava a casar os desafios que me colocara enquanto profissional prematuro e o perfil do aluno que tinha diante de mim com uma bibliografia e um conteúdo, mas ainda restava a questão do comportamento. Como agir? De que modo me endereçar aos estudantes? O que eu podia exigir deles, quais leituras, exercícios? Como lidar com o não cumprimento de tarefas? A maior parte deles era tinha mais idade do que eu, o que trazia muitas dificuldades adicionais. Alguns passaram a infância trabalhando e estavam, pela primeira vez na vida, com algum tempo livre para se dedicarem aos estudos. Perto deles eu era uma criança privilegiada. Minha imagem social, portanto, era bem diferente da que eu experimentava na universidade. Estudante, eu mal tinha dinheiro para comprar livros, comia no refeitório universitário a preços baixíssimos e andava de ônibus. Na escola, era um pequeno burguês vindo de uma das melhores universidades do país. Pertencia àquele número irrisório que frequentava ensino superior.

Para adicionar ainda mais dificuldades às que já enfrentava, meus professores na USP não eram modelos diretamente aplicáveis ao contexto que eu enfrentava. Eles não se apresentavam propriamente como parte do sistema estatal. Endossavam ou eram autores de críticas ao modo de funcionamento do Estado. $\mathrm{O}$ faziam, porém, embasados em um conjunto de autores bastante clássicos, na maioria estrangeiros, muitos deles citados diretamente em línguas que não estudei na escola pública, em aulas de quatro horas seguidas de explanações densas, muitas vezes sem que fosse admitida qualquer interrupção.

Eu aprendi, logo nos primeiros anos de escola, a cantar hinos militares e a marchar. Estar na USP, naquele ambiente, parecia um antídoto ao meu próprio passado. Eu revia tudo o que passei e encontrava explicações, percebia regularidades, entendia orientações gerais da educação, encontrava argumentos para responder a desgostos que eu nem sabia discernir antes de entrar no ensino superior. Eu me refazia psicologicamente. Meus mestres na universidade compunham a esquerda perseguida cruelmente, eram a referência para a mudança. Mas a base a partir da qual a propunham provocava em mim, muitas vezes, uma nova e forte sensação de opressão. Os elogios e o prestígio eram destinados justamente àqueles mais distantes das origens populares e dos formados em escolas públicas. Estava reservado a filhos de famílias que, para mim, pertenciam à classe dos patrões. 
Como conciliar as brincadeiras, as sugestões, o bom humor das novas pedagogias, a missão democrática e emancipatória da educação, o incorporar o universo do aluno no aprendizado, com aquele comportamento rígido dos meus mestres? Havia algo de paradoxal nisso tudo e os estudantes elaboravam um vasto conjunto de hipóteses para torná-lo mais explícito: os mais otimistas se encantavam com o que nos parecia uma vastidão de conhecimentos jorrando da boca dos nossos professores, consideravam quase uma benção poder conviver com eles; os mais pessimistas diziam que eram todos hipócritas, que estavam apenas disfarçadamente interessados em suas carreiras individuais. Muitos dos que haviam chegado à universidade melhor preparados que a maioria, simplesmente não viam problema algum. Para eles, aquele era o seu contexto cultural doméstico e, supunham, também o de todos.

Felizmente a sala de aula não foi único acesso disponível aos meus mestres. Eles mesmos, imagino hoje, tinham dúvidas, inseguranças, incertezas, cuja natureza era similar àquelas que eu enfrentava como professor. Qual o melhor método, conteúdo, conduta, para esse grupo? Como lidar com ele? Não foram poucos os que se dedicaram a conversar individualmente com os alunos. Uma professora, ex-funcionária da Aliança Francesa, ao se dar conta que muitos de nós nunca tinham frequentado um curso de língua estrangeira, organizou gratuitamente uma classe de francês. Lembro com muito carinho de outra mestra que, vendo meus esforços naufragarem em sérias dificuldades de leitura e redação, convidou-me para algumas conversas nas quais me ensinou a redigir um resumo, me deu conselhos de estudos de escrita e acompanhou atentamente meus progressos. Se concluí a graduação, foi graças à sensibilidade e profissionalismo dessas pessoas. Por causa desses momentos eu conseguia dar sentido à minha presença na universidade, eu recuperava a atenção às aulas e acreditava que podia superar as dificuldades encontradas.

Essas atitudes me mostraram, na prática, o sentido de uma das principais lições do livro Cuidado Escola!: o centro das nossas preocupações deve ser o destinatário do processo de formação, o estudante, considerado do ponto de vista cognitivo, emotivo e social, e essa atenção deve se reverter numa constante reflexão sobre o papel do educador. Levo comigo essa frase como princípio último de tudo o que faço.

Mesmo com todas essas particularidades dos meus primeiros anos de trabalho, não preciso de grandes exercícios introspectivos para rever a mim mesmo naqueles tempos: quando adentro as salas de aula na UFRGS, onde trabalho hoje, deparo-me com rostos e inquietações que lembram minhas motivações e inseguranças de estudante. Um aluno, recentemente, durante uma roda de debate sobre um texto de Herbert Marcuse, perguntou: é possível ensinar sem ser autoritário? Outro respondeu: é preciso construir a autoridade do saber. Depois, silêncio. A preocupação com a divulgação do conhecimento sociológico às camadas mais pobres da população continua igualmente forte e presente. Como nos despojarmos dos papéis tradicionais e autoritários da profissão sem cair numa relação amistosa e irresponsável que valida qualquer vontade acima dos procedimentos pedagógicos? 
Se deixasse por conta da sensação que me causa a arquitetura das nossas universidades, diria que nada mudou. As plantas dos campi federais e de algumas estaduais são muito parecidas, foram elaboradas durante a ditadura militar. A memória que tenho das salas de aula em São Paulo, na USP, onde me formei, e a imagem que vejo nas que encontro aqui em Porto Alegre, são, constrangedoramente, semelhantes. O mesmo caixote de cimento armado que irrompe o verde do gramado e das copas frondosas, as mesmas cadeiras antiergonômicas por cujas bordas os cadernos e livros despencam, o mesmo piso vinílico dos postos de saúde, o mesmo calor e o mesmo frio intensos que atravessam as paredes estreitas e as janelas mal vedadas. Até o jardim é semelhante, espalhados aqui e ali, uns bancos solitários de cimento duro que desafiam a resiliência do corpo fatigado. Se a distancia paisagística que separa meu passado e meu presente parece ser a dos passos entre um prédio e outro num jardim intemporal, se os dilemas continuam semelhantes, as referências simbólicas através das quais os alunos os enfrentam mudaram radicalmente.

Hoje eu teria bastante dificuldade em explicar porque um filme do Godard, ou outras produções artísticas, são revolucionárias em termos políticos. Não contaria com uma disposição imediata, ainda que ingênua (como era a minha), de considerá-lo dessa forma. A crítica social é associada a discursos muito diretos sobre igualdade e direitos e a recusa do que não é compreendido é mais veemente. Muitos alunos não têm qualquer constrangimento em perguntar, revoltados, porque investir em arte, porque financiar uma atividade elitista que o cidadão comum não consegue entender. Quem faz esse tipo de indagação, frequentemente, são os que se pensam de esquerda, contrários e críticos a um sistema opressor que precisa ser democratizado. Mencionar o concretismo, a bauhaus ou o dadaísmo pode soar exibicionismo desnecessário.

Para um professor, essas transformações representam um desafio enorme porque o obrigam a reconstruir uma série de práticas e referências. As meias palavras relativas à arte que despertavam uma cumplicidade invisível, mas efetiva, a leitura de sinais sobre as simpatias que poderíamos ter entre os colegas a partir dos posicionamentos deles frente à produção artística, a afirmação direta e incisiva do valor dessa atividade nos momentos em que isso era permitido, a disposição despertada nos ouvinte quando esse tema era mencionado, tudo isso mudou, preciso construir minha identidade pública através de outros artifícios e associações.

Uso meias palavras em circunstâncias em que era direto e, quando quero ser direto, num ambiente que me é simpático, sou obrigado a embasar o que digo com uma solidez de casos muito bem detalhada. Ou seja, preciso rever minhas palavras e seus efeitos nos públicos diversos. Para falar sobre arte, às vezes tenho que recuperar alguma evidência histórica muito forte do seu conteúdo contestador, como a exposição Arte Degenera, realizada em Munique em 1937, na qual os nazistas ridicularizaram obras modernistas com cartazes depreciativos afim de ressaltar valores como a pureza racial e o militarismo. 
Essas mudanças podem ser estendidas para o modo como concebemos, de modo geral, nossa profissão. A alteração pode ser marcada pelo papel que a publicação tem na formação e na atividade do professor. Até mais ou menos 1990, não se esperava que um recém doutor publicasse mais de um artigo durante sua carreira e, de qualquer jeito, esse não era um critério de avaliação de sua capacidade produtiva. Hoje em dia, espera-se que os graduandos publiquem e participem de congressos e eventos em geral. O problema de todo dado quantitativo não é propriamente o dado, é ele ser tomado apenas em referência a si mesmo. O que quero relembrar é que a escola e a universidade, e parece que esquecemos essa obviedade, estão inseridas num sistema de ensino. Publicava-se pouco não porque os profissionais da educação eram improdutivos, mas porque o valor da produção estava em outro lugar. Claro que havia professores que sequer ministravam aulas, os vínculos empregatícios o permitiam ou então usavam de artifícios diversos para se ausentarem, com comprar licenças médicas (no Largo de Pinheiros, em São Paulo, havia muitas placas com ofertas de atestados médicos de dispensa de trabalho). Na universidade pública, nem mesmo redução de salário sofriam. Portavam-se como detentores de cargos nobiliárquicos sem qualquer obrigação de desempenho. Uma vergonha, para dizer o mínimo. Mas havia, por outro lado, espaço para certo idealismo, um elogio discreto e marcante da humildade.

Meus professores, por exemplo, não inseriam textos de sua autoria nas disciplinas que ministravam, exceto em raros momentos bem justificados, precedidos de desculpas e com dispensa de apresentação por parte dos alunos. A prática era considerada antiética por uma razão muitos simples: a presença do autor professor, em nível hierárquico distinto, inibe a absorção crítica, impede a reação sincera do aluno e compromete o aprendizado. Quando iniciei na docência universitária, já doutor, me foi fornecida pela secretaria da faculdade, como referência, o programa do colega que me antecedeu. Naquele momento eu vi, pela primeira vez, textos de autoria do professor encarregado da disciplina na bibliografia da mesma. Fiquei chocado. Achei que era uma situação particular, um erro. De lá para cá, já encontrei várias disciplinas compostas exclusivamente com a produção do ministrante.

De todas as adaptações a que fui submetido, a mais acentuada é relativa à minha apresentação pessoal. Uma consequência da divulgação dos dados sobre publicação e do seu estatuto na avaliação do profissional de ensino é que com frequência o olhar de alunos e colegas sobre mim recai prioritariamente na qualidade de autor. A variedade de posições que podíamos assumir é menos considerada. Não somos mais vistos como capazes de explicar bem um assunto, conhecedores deste ou aquele pensador, detentores desta ou daquela inclinação teórica ou ética, tradutores ou divulgadores de uma linha de pensamento. As estatísticas relativas a publicações precedam qualquer outra impressão. Se quero ser reconhecido por outras atividades da profissão, preciso ultrapassar essa minha introdução prévia, tenho que pautar a relevância dessas alternativas e estabelecê-las como um valor que justifique a relação, sou obrigado a constantemente construir uma ética de contato. 
A expectativa, antes do fim da ditadura, era mais aberta por uma simples razão, havia sempre a chance do professor ter sido silenciado, o que tornava extramente grosseiro, injusto e insensível a acusação de incompetência com base numa visibilidade numérica. Decorre dessa possibilidade o respeito aos que procuravam um nicho onde pudessem exercer sua competência. O principal lugar visado para isso era a atividade do magistério. Ela aparecia como opção de empenho, qualidade e compromisso sério com o conhecimento. A aula, pelo que encontro no meu dia a dia, perdeu muito desse caráter. Não se trata de saudosismo. Havia quem aproveitasse desse clima geral para desculpar ausências, despreparo, fingir dificuldades. Da mesma forma que hoje muitos dos meus colegas se queixam insistentemente de obrigações que, parte delas, são impostas por eles mesmo, não pelos órgãos de controle do governo. Já presenciei várias situações nas quais um professor foi tratado como moralmente desprezível ou traidor por não ter cumprido determinada meta produtiva, como se não tivesse o direito de escolher sua própria identidade intelectual.

Do ponto de vista da estrutura universitária, o mais chocante, para mim, é a possibilidade de uma faculdade ou curso serem muito bem avaliados sem que o aluno receba qualquer benefício dessa aparente qualidade. Tudo o que fazemos hoje é registrado e contabilizado. Surpreendentemente, ministrar aulas não rende pontos. Assim, acontece com frequência do professor ausentar-se da sala de aula, dedicar-se quase que integralmente a gerenciar projetos, administrar grupos de pesquisa ou escrever artigos. Há uma falácia grave que compromete o ensino hoje: supor que um conjunto de publicações é indicativo de produção acadêmica e que isso gera automaticamente benefício aos alunos. Nenhuma das duas consequências é necessariamente verdadeira. Publicações podem ser repetitivas ou decorrer de alianças casuísticas, como trocas de favores. $\mathrm{O}$ aluno, por seu turno, pode ficar completamente ao largo do que acontece nos núcleos de pesquisa, principalmente os mais carentes, os que não têm condições de assumir períodos longos de trabalho com bolsas baixas ou sem remuneração alguma em projetos aprovados pelos órgãos de fomento à pesquisa.

Há muitas outras mudanças: as novas tecnologias, o sistemas de cotas e bolsas, etc. A impressão que tenho, entretanto, sem querer questionar o significado das últimas para a democracia, é que elas não resolvem as questões essenciais ao bom desempenho de um professor. Os problemas, nesse sentido, continuam muito parecidos. Noutros tempos eu lamentava não termos mais bibliotecas da mesma forma que hoje lamento a exclusão digital (e continuo lamentando a falta de bibliotecas). O dilema entre formar especialistas para continuarem na própria universidade ou trabalhadores para o mercado de trabalho ainda está presente na cabeça dos alunos e nos vícios institucionais; a educação básica continua vítima de grandes projetos que não alteram quase nada. Com a plataforma Lattes avançamos muito no profissionalismo e na internacionalização da produção brasileira. Ganhos consideráveis que devem ser preservados. Perdemos, por outro lado, a capacidade de julgar para além de critérios numéricos, sacrificando o 
compromisso ético do profissional, que não pode jamais ser quantificado, deve ser avaliado a partir das condições específicas de cada um.

Já transcorreram 30 anos desde a primeira vez que entrei em sala de aula como professor, mas sempre me lembro daquele primeiro grupo. Tentei muitas propostas com eles: ler diretamente autores clássicos, utilizar notícias de jornal, provocá-los com temas inusitados, exposições longas, grupos de discussão, solicitar pesquisas, etc. Se me perguntarem o que é que deu certo, eu diria que absolutamente nada disso. Minhas equações estavam completamente equivocadas. Os momentos em que consegui atingir com mais profundidade os alunos e despertar neles maior paixão e dedicação às aulas e aos estudos, não foi quando melhor resolvi conteúdos, programas ou referências bibliográficas. Eu consegui motivá-los todas as vezes que transmiti a confiança sincera de que eles tinham condições de superar suas próprias limitações, de que poderiam se tornar excelentes profissionais e de que eu estava fazendo o melhor de mim como educador e pesquisador para contribuir com seu crescimento intelectual. Esse esforço, como base para o diálogo, é o que aprendi, na minha trajetória, como o investimento mais fundamental que podemos fazer nesta profissão.

Um professor, conforme coloquei no começo desse relato, sempre coloca um pouco de si mesmo em tudo o que faz. Os alunos percebem esse esforço muito claramente e minha experiência me diz que retribuem com igual respeito. Ler, publicar, participar de congressos, etc, deveria estar a serviço dessa dedicação. Parece, no entanto, que ganharam uma autonomia vazia, como se bastassem a si mesmos.

Depois de tudo que passei, eu reformularia as perguntas que acho importantes da seguinte forma: o quanto ganhamos em termos de rendimento nas atividades pedagógicas? Os empecilhos em colocar as coisas dessa forma simples, direta e abrangente, decorrem da não identificação de nichos específicos de publicação ou público alvo para as eventuais respostas. Essa pergunta não cabe especificamente a professores universitários ou aos de ensino fundamental e básico, mas a ambos, porque diz respeito à formação para o magistério, à relação entre universidade e a escola, entre o agir e o preparar-se para ele. Está ligada a valores, a princípios que fazem de todos nós, professores, uma categoria única.

Foi com Barthes e outros que aprendi a lição fundamental da desconfiança de toda fala ou texto. Não há outra forma de resistir a qualquer imposição autoritária, venha ela de um sistema de governo, de um órgão, de uma faculdade, departamento, colega ou mesmo da nossa própria autocensura. A ordem se impõe sobre as necessidades humanas e democráticas quando as pessoas abrem mão do espírito crítico. Quando sofremos repressão à livre manifestação ou quando aceitamos um índice numérico de quem comunica como atestado suficiente da qualidade do exposto.

Não tenho ponto final a interpor. Foucault, em sua primeira aula no Collège de France, afirmou: gostaria que uma voz sem nome o precedesse. A humildade deste grande mestre nos mostra que somos sempre vozes em curso, 
um emaranhado de sons e letras que envolve as do professor que nos precedeu no mesmo dia, nos anos anteriores, nas perguntas dos alunos e no que pensam em silêncio, no que dirão quando eles mesmo adentrarem as salas como professores. Todas elas estão ali, em qualquer instante da nossa carreira e em qualquer posição que ocupemos. É assim que entendo a colocação de Paulo Freire de que o centro da nossa atividade é o aluno: aquele a quem nos dirigimos, aquele que fomos e aos que darão continuidade à nossa voz no futuro.

\section{Endereço para correspondência:}

Caleb Faria Alves

Av. Bento Gonçalves, 9500 - Prédio 43311

91509-900 Porto Alegre, RS, Brasil

Recebido em: abril/2014

Aceito em: maio/2014 